\title{
Criminal Blame, Exclusion and Moral Dialogue
}

\section{Costanza Porro ${ }^{1}$ (1)}

Accepted: 21 January 2021 / Published online: 14 February 2021

(C) The Author(s) 2021

\begin{abstract}
In her recent book The Limits of Blame, Erin Kelly argues that we should rethink the nature of punishment because delivering blame is, contrary to the widely held view, not among the justifiable aims of a criminal justice system. In this paper, firstly, I discuss her case against criminal blame. Kelly argues that the emphasis on blame in the criminal justice system and in public discourse is one of the main causes of the stigma and exclusion faced by those convicted for a crime. This claim might appear puzzling and, while she provides other convincing arguments against criminal blame, Kelly does not extensively defend this particular argument. To offer support for this view, I reflect on the often overlooked distinction between moral blame and criminal blame to show how the latter, unlike the former, is exclusionary and stigmatising. Secondly, I address the claim put forth by Kelly that blame should play no role in the criminal justice system at all. In light of her argument about the optional nature of moral blame, I explore the possibility that the state should leave open to victims the option to blame criminal wrongdoers in restorative justice conferences. I argue that in such contexts blame would not have the same exclusionary features of criminal blame in traditional settings and that it could serve some valuable aims articulated by communicative theories of punishment, such as the restoration of moral relationships.
\end{abstract}

Keywords Punishment $\cdot$ Blame $\cdot$ Restorative justice $\cdot$ Exclusion

Costanza Porro

costanza.porro@gmail.com

1 Institute of Philosophy, University of Hamburg, Hamburg, Germany 


\section{Introduction}

Erin Kelly's recent book, The Limits of Blame, has two virtues that the philosophical literature on criminal punishment too often fails to combine: it is a philosophically sophisticated and very well-argued book that is also an important and timely, even urgent, investigation into a central problem of many criminal justice systems, including of course that of the United States. ${ }^{1}$ The criminal justice system's overreaches, excesses, and the stigma and often permanent exclusion of those who are convicted for a crime are the issues that Kelly addresses. Her diagnosis is that the responsibility for these grave harms and injustices is, at least partly, to be attributed to the "culture of blame" that permeates not only public discourse and the dominant narratives on crime but also finds strong echoes in theories of punishment. The central idea is that correct criminal conviction necessarily implies blameworthiness and, according to retributivists, that punishment is morally deserved. Kelly argues that we should rethink our theories and practices of punishment and the way we attribute criminal responsibility. We should imagine a criminal justice system that punishes without conveying blame.

\section{Why is Criminal Blame Stigmatising?}

Let me begin with a discussion of Kelly's case against blame. Kelly presents three main arguments for eliminating blame from the criminal justice system. Firstly, she argues that the existing criteria of legal guilt do not match criteria of moral blameworthiness and that criminal law should not be reformed in this direction. ${ }^{2}$ Secondly, she criticises the influential view that blame is the only respectful and engaged response to wrongdoing. Thirdly, she argues that because moral blame is optional and it is up to the victim to decide whether to blame the wrongdoer, it is an inappropriate foundation for rules of the criminal justice system. This is because these rules apply coercively and should therefore be justified through public reasons acceptable to all. ${ }^{3}$ While these are valid arguments against criminal blame, they do not illuminate what I take to be another central reason behind Kelly's rejection of criminal blame: the idea that considering criminal wrongdoers morally blameworthy, and blaming them, lends support to their stigmatisation and exclusion as well as their excessive punishment.

While Kelly does not deny that other factors, such as existing racial, social and economic injustices, contribute to the stigmatisation of those who are convicted for a crime, she argues that blame-centric theories, as well as retributivist ones, are partly responsible for their exclusion. Kelly dedicates part of her introduction to the discussion of the ways in which criminal blame leads to stigma, arguing that blame

\footnotetext{
${ }^{1}$ Erin Kelly, The Limits of Blame: Rethinking Punishment and Responsibility (Cambridge, Mass.: Harvard University Press, 2018).

2 Kelly, chap. 1 and 2.

3 Kelly, chap. 3 and 4.
} 
goes beyond the assessment of wrongdoing and involves a judgment on the moral character of the actor, which marks the person as defective, tainted and morally inferior. In virtue of this assessment of moral inferiority, the difference between those who are convicted for a crime and other citizens is overstated and the former are treated as an undifferentiated, morally reprehensible group to be kept apart from the rest of the community. ${ }^{4}$

This account of blame seems to contradict many contemporary theories of blame, for two reasons. Firstly, while it is often argued that blame involves an assessment of people's character and the quality of their will, not many would agree that when one is found blameworthy a judgment on their moral inferiority is issued. This is partly because this view relies on a jump from a judgment of one's ill will or bad character in a particular respect, such as in regard to one's lack of integrity, to an overall assessment of one's character as morally defective. Often when we blame others in our interpersonal interaction, we judge them to have shown ill will, but we do not always derive conclusions about their overall badness, much less about its irredeemable nature. In other words, while blame does involve relating a person's actions to her qualities as a person, the conclusion that one is morally inferior seems rather hasty. ${ }^{5}$

Secondly, and more importantly, the view that blame involves distancing and withdrawal from a person is defended by those, like Tim Scanlon, who believe that blame involves acknowledging that someone's wrongdoing has impaired one's relationship with them. ${ }^{6}$ Christopher Bennett adopts Scanlon's theory of blame in his discussion of punishment and argues that criminal blame is the partial suspension of the attitudes of respect and concern that would otherwise be owed to someone with whom we are in a political relationship. ${ }^{7}$ One might wonder whether, even under this model, the attitude of blame necessarily leads to stigma and exclusion. After all, Scanlon explicitly rejects the idea that the basic respect owed to others qua member of the moral community can ever be lost as a result of blame. ${ }^{8}$ However, it has been correctly pointed out that the consequence of the adoption of a Scanlonian conception of blame to the criminal domain is an exclusionary theory of punishment, as it requires the partial suspension of the political relationship. ${ }^{9}$

Setting aside Scanlonian theories of blame, many other influential accounts of blame do not consider distancing from the wrongdoer as a component of this attitude. Interestingly, this is also true of emotional theories of blame, which regard

\footnotetext{
4 Kelly, 09-11.

5 For a discussion of the different views on the ways blame is directed to character see George Sher, In Praise of Blame (Oxford: Oxford University Press, 2006), chaps 2-4.

6 Thomas Scanlon, Moral Dimensions: Permissibility, Meaning, Blame (Cambridge, Mass.: Harvard University Press, 2008), chap. 4.

7 Christopher Bennett, The Apology Ritual: A Philosophical Theory of Punishment (Cambridge: Cambridge University Press, 2008), chap. 5.

8 Thomas Scanlon, 'Interpreting Blame', in Blame: Its Nature and Norms, ed. D. Justin Coates and Neal A. Tognazzini (Oxford; New York: Oxford University Press, 2013).

9 Kimberley Brownlee, 'Retributive, Restorative and Ritualistic Justice', Oxford Journal of Legal Studies 30, no. 2 (July 2010): 7-9.
} 
emotional responses, rather than a judgment or a desire, as central to blame. While some believe that what makes blame stigmatising is the expression of negative reactive emotions, Susan Wolf, one of the leading proponents of this approach, defends the idea that blame does not involve any withdrawal from the relationship. ${ }^{10}$ While blame is an emotionally charged response which often encompasses anger, it is a dialogical response which involves the wrongdoer and can thereby play a positive role in the context of intimate relationships. The emotional aspects of blame and its stigmatising effects are not necessarily interconnected, and reactive emotions, such as anger and resentment, do not necessarily sever relationships and foster exclusion. In light of these remarks, it seems hard to argue that it is simply in virtue of the nature of blame that exclusion and stigma follow from it.

\subsection{On the Difference Between Criminal Blame and Interpersonal Blame}

While this could make us doubt Kelly's claims that the central role of blame in the criminal justice system is partly responsible for the stigma, exclusion and overpunishment of those convicted for a crime, her view is-to my mind-correct. The reason lies in the often-overlooked distinction between moral and criminal blame, which makes the latter, unlike the former, inherently stigmatising and exclusionary. While theorists tend to treat moral and criminal blame alike and adopt their preferred conception of moral blame to the criminal domain, ${ }^{11}$ there are crucial differences between these two domains and the relationships and practices which they involve. These differences do not depend, as David Shoemaker recently suggested, on the fact that the relationship between the state and its citizens is an asymmetrical authority relationship, while interpersonal blaming exchanges typically happen within symmetrical authority relationships. ${ }^{12}$ Instead, they lie in unique features of the relationship between the state and its citizens, and the nature of criminal law. ${ }^{13}$ In my view, there are four main considerations which separate moral from criminal blame, making the latter, unlike the former, exclusionary and therefore objectionable. The four considerations are influence, type of conduct, nature of the judgment, and upshots of blame.

\footnotetext{
${ }^{10}$ Susan Wolf, 'Blame, Italian Style', in Reasons and Recognition: Essays on the Philosophy of T. M. Scanlon, ed. R. Jay Wallace, Rahul Kumar, and Samuel Richard Freeman (New York: Oxford University Press, 2011), 332-47.

11 See for instance Bennett, The Apology Ritual. Antony Duff, 'Legal and Moral Responsibility', Philosophy Compass 4, no. 6 (December 2009): 978-86. Victor Tadros, Criminal Responsibility (New York: Oxford University Press, 2007).

12 David Shoemaker, 'Blame and Punishment', in Blame: Its Nature and Norms, ed. D. Justin Coates and Neal A. Tognazzini (Oxford; New York: Oxford University Press, 2013), 100-118.

13 For arguments against the view that the practices of the criminal law are just formalised version of the practices of morality and a defence of the claim that the problem of punishment should be addressed from a political theory, rather than moral philosophy, perspective see Corey Brettschneider, 'The Rights of the Guilty: Punishment and Political Legitimacy', Political Theory 35, no. 2 (April 2007): 175-99, https://doi.org/10.1177/0090591706297714. and Malcolm Thorburn, 'Constitutionalism and the Limits of the Criminal Law', in The Structures of the Criminal Law, ed. R. Anthony Duff et al. (Oxford: Oxford University Press, 2011), 85-105.
} 
Starting with the first consideration, influence, a core point of distinction between these two cases is that the state has a unique influence on the standing of citizens. This influence is exercised in various ways, two of which are relevant for our discussion. Firstly, the state can be criticised because of the attitudes expressed through its actions and the message that its policies convey because these attitudes can undermine citizens' standing. ${ }^{14}$ When state action, and the law, send the message that members of certain groups are not equal members of society, the state fails to treat them with respect and changes its relationship with them. In doing so, the state imposes on some of its citizens a new, lower, status. Secondly, state impact on the status of citizens is also exercised through its influence on the judgment and attitudes of other members of the community. Especially in circumstances when the state enjoys a good level of social legitimacy, its judgment about particular groups is likely to influence others' judgment towards members of that group. ${ }^{15}$ In the case of a blame-centric criminal justice system, the judgment conveyed by the state that those convicted for a crime have shown themselves to be morally defective has a significant impact on the attitudes of other citizens towards them. Of course, the same cannot be said of paradigmatic cases of interpersonal blame, which take place in the close circle of personal relationships and are conveyed by less influential agents. ${ }^{16}$

Moving to the second consideration, the type of conduct, criminal blame can be distinguished from paradigmatic instances of moral blame in virtue of the type of conduct that it targets. The criminal law addresses actions whose wrongfulness is the concern of the state and the community because they are taken to disregard some of its core interests or values. ${ }^{17}$ Therefore, if one is found to be criminally guilty in a blame-centric criminal justice system, the judgment that is sent by the state is that one has shown a lack of commitment to public values. ${ }^{18}$ Such judgment is of particular relevance because of its gravity, and because it signals to other members of the community that those convicted of crimes are lacking in a dimension which is central to the political relationship. Unlike many interpersonal cases, where blame is a private matter in which only agents who stands in particular relationships with the wrongdoer have a standing to blame, the violation of these public standards is under the jurisdiction of all other member of the community, and blame is expressed by the state on their behalf. ${ }^{19}$ An interesting and related feature of the criminal law is that, in comparison to interpersonal morality, the room for moral disagreement is

\footnotetext{
14 Elizabeth S. Anderson and Richard H. Pildes, 'Expressive Theories of Law: A General Restatement', University of Pennsylvania Law Review 148, no. 5 (May 2000): 1503-75.

15 The literature on law and social norms can offer some insights on the way in which the law, and the message sent by the state through it, can shape social norms and judgments about particular action and categories of people. Lawrence Lessig, 'The Regulation of Social Meaning', The University of Chicago Law Review 62, no. 3 (1995): 943-1045; Cass R. Sustein, 'On the Expressive Function of Law', University of Pennsylvania Law Review 144, no. 5 (1996): 2021-53.

16 This consideration should invite some caution in cases like public shaming, especially online public shaming, where the influence of different agents combined becomes less negligible.

17 Kelly, The Limits of Blame, chap. 5. S.E. Marshall and R.A. Duff, 'Criminalization and Sharing Wrongs', The Canadian Journal of Law and Jurisprudence 11, no. 01 (January 1998): 7-22.

18 For an explicit defense of this view see Bennett, The Apology Ritual.

19 Kelly, The Limits of Blame, 77.
} 
reduced: these actions are such that their wrongfulness should be agreed upon by the community as a whole. Moreover, the criminal trial is supposed to act as a factfinding process that individuals delegate to the state and the result of which, despite the rather common occurrence of wrongful conviction, is usually taken at face value. This renders criminal blame significantly different from cases of moral blame where there is often room for moral pluralism and discussion around the wrongfulness of the conduct, as well as the culpability of the agent. ${ }^{20}$

In light of the first and the second consideration, the judgment expressed by the state when blaming those who are convicted for a crime has two features, which I call the spill-over effect and the eclipsing effect, and which gives rise to the third consideration, the nature of the judgment. Firstly, the judgment of criminality has a spill-over effect insofar as it easily becomes a judgment about other aspects of a person, first and foremost their general morality, or lack thereof. From knowing that one has committed a crime, people inside and outside the criminal justice system tend to conclude that one lacks a firm commitment to public values or even a moral compass. Secondly, this judgment is likely to have an eclipsing effect on other domains of esteem: learning that one has committed a criminal offence tends to obscure other dimensions of one's life, including other possible ways in which one has made a positive contribution to society. ${ }^{21}$ These effects are further enhanced by the fact that in cases where the status of one as having been convicted for a crime becomes known by people outside one's close social circle, this is often one of the few, and the most salient, piece of information that others have about the person. Therefore, the judgment of criminality is not tempered by other considerations about the person, their life and psychology, including disadvantage, hardship and trauma that they might have faced. This judgment has two features, the spill-over and eclipsing effects, in light being conveyed by a uniquely influential authority-as illustrated by the influence consideration-and on a uniquely relevant matter, identified by the type of conduct consideration. It is in virtue of these two features that criminal blame becomes an overall judgment on the character of those convicted for a crime, who are thus regarded as morally inferior, tainted or defective persons. This explains the jump from a particular judgment of blameworthiness, which only refers to one having shown ill will or bad character in connection to a particular action and trait, to an overall assessment of a person's character. This is related to the tendency to regard those who are convicted for crime as a uniform and undifferentiated group of morally reprehensible people, often ignoring the very significant differences in the level and nature of wrongness of different criminal acts and blameworthiness of these agents. ${ }^{22}$

\footnotetext{
${ }^{20}$ I do not want to suggest that in cases of criminal blame there is no room for disagreement about whether a particular conduct should be criminalised as well as the outcome of criminal trials, however, the level of disagreement appears to be lower that in many cases of interpersonal blame.

${ }^{21}$ Kimberley Brownlee, 'Don't Call People "Rapists": On the Social Contribution Injustice of Punishment', Current Legal Problems 69, no. 1 (2016): 327-52, https://doi.org/10.1093/clp/cuw009.

${ }^{22}$ Kelly, The Limits of Blame, 9-11.
} 
The spill-over and eclipsing effects and their stigmatising impacts are even more marked if criminal blame is conveyed against the backdrop of existing social norms of exclusion and stigma. Firstly, many offenders belong to social groups which are already stigmatised and disparaged by the state and other citizens, such as ethnic minorities. In this case, their relationship with the state is shaped by rejection and hostility even before offending, and the blame received afterwards is understood according to the nature of that previous relationship and reinforces the existing exclusion. Secondly, existing norms of exclusion towards those who are convicted for a crime shape the relationship between the state and all those who are convicted: in these cases, it is even more fitting to interpret criminal blame as an exclusionary attitude of the state. Moreover, in such circumstances, criminal blame reinforces and strengthens the pre-existing exclusionary attitudes of fellow citizens towards those convicted of a crime.

The final consideration about criminal blame concerns the upshots of blame. Moral blame can take a variety of forms: it can be either unexpressed or expressed and encompasses different types of attitudes, including more dialogical and inclusionary responses and more punitive and exclusionary ones. Similarly, criminal blame can be expressed and conveyed in different ways through the criminal justice system. However, while the question of whether the expression of blame can justify hard treatment is debated, ${ }^{23}$ many take punishment to be pro tanto justified precisely because it expresses blame for criminal offenses. Moreover, according to the retributivist maxim, hard treatment and suffering are imposed on those convicted for a crime because they morally deserve to endure it. The necessary connection between criminal blame and punishment, and hard treatment, makes it importantly different from paradigmatic instances of moral blame and invites further caution in thinking about the conditions of its appropriateness. ${ }^{24}$ The fact that blame is often used as the grounds of punishment does not, of course, exhaust the question of which types of punishment and infliction of suffering can be justified by appealing to it. As in the case of interpersonal blame, where one can take a stand about the ways in which it can be expressed, proponents of a blame-centric criminal justice system can, and often do, argue that certain types of exclusionary punishment and collateral consequences cannot be justified as acceptable expression of blame. Nevertheless, theorists sometimes do invoke blame and desert to justify exclusionary penal practices, such as penal disenfranchisement. ${ }^{25}$ More importantly, the possibility of misuses and abuses of the appeal to blame and moral desert in the justification of punishment, which is evidenced in many existing criminal justice systems, should make one wary about proposing blame or desert as the rationale of punishment. This is

\footnotetext{
${ }^{23}$ See for instance Matt Matravers, 'Duff on Hard Treatment', in Crime, Punishment, and Responsibility, ed. Rowan Cruft, Matthew H. Kramer, and Mark R. Reiff (Oxford University Press, 2011).

24 Interestingly, this is might be true also of other contexts where blame often acts as a justification of punishment, such as schools or the relationship between parents and children.

25 Christopher Bennett, 'Penal Disenfranchisement', Criminal Law and Philosophy 10, no. 3 (September 2016): 411-25. Some have also argued that the state response to crime should involve stigmatising condemnation. See for instance Douglas Husak, 'Lifting the Cloak: Preventive Detention as Punishment', San Diego Law Review 48 (2011): 1173-1204.
} 
the case if one understands, as-in my view-Kelly correctly does, the philosophy of criminal law as a discipline does not transcend the realities of actual criminal justice systems, and should speak to the problems and challenges that they face.

In light of these four considerations, we can appreciate the extent to which criminal blame differs from moral blame and fully understand its exclusionary and stigmatising nature. In conveying criminal blame, the state causes or reinforces the exclusion of those convicted for a crime. In so doing, as the state has a much more stringent obligation than private individuals to treat citizens as equals and show them equal respect and concern, it systematically disregards one of its core duties.

\section{A Criminal Justice System Without Blame?}

In this section, I discuss Erin Kelly's case for a criminal justice system without blame. My main goal is to address the question of whether foregoing blame necessarily involves the abandonment of important aims of punishment and the criminal justice system. The aims I am referring to are those articulated by expressivist and communicative theories of punishment, which revolve around the need of the state to engage in condemnation of crime as well as a moral dialogue with the offenders. In Kelly's view, the rationale for punishment in a just society would be harm reduction but, while she correctly rejects retributivism, she acknowledges the importance of certain expressivist and communicative aims. Kelly argues that these communicative aims can be captured by her account because they can be achieved by expressing moral condemnation for actions without conveying any judgment of people. In her view, by criminalising and punishing certain acts, the community publicly condemns these acts. In so doing, it acknowledges the harm done to the victims and vindicates the law. This convincing argument serves to disable an objection to her account based on the idea, often defended by advocates of blame, that foregoing blame signals a lack of commitment to moral values because valuing morality and blaming are inherently connected. ${ }^{26}$ What Kelly's proposal shows is that the community's commitment to its core values and laws can be expressed and reinstated by expressing censure towards acts without resorting to blame towards people.

To this, I would add another consideration. An important insight of expressivist and communicative theories of punishment is the idea that citizens are treated with the respect owed to members of the political community when they are addressed with the language of moral reasons and the values of the political community. ${ }^{27}$ Rather than being related to as merely self-interested rational agents, who would refrain from conduct because of the penalty associated with it, when the state conveys the wrongness of an action through criminalisation it attempts to morally (and

\footnotetext{
${ }^{26}$ Sher, In Praise of Blame, chap. 7; Christopher Evan Franklin, 'Valuing Blame', in Blame: Its Nature and Norms, ed. D. Justin Coates and Neal A. Tognazzini (Oxford; New York: Oxford University Press, 2013), 207-23.

27 Antony Duff, Punishment, Communication, and Community (Oxford; New York: Oxford University Press, 2001), 78-79.
} 
not merely rationally) persuade them to refrain from it. While some, most notably Anthony Duff, ${ }^{28}$ argue that as long as the state addresses its citizens in the language of deterrence it treats them with disrespect, many claim that a mixed system which combine moral and prudential reasons for not committing crime-like the one proposed by Kelly-conveys respect towards members of the community. ${ }^{29}$

\subsection{Restorative Justice, Restoration of Moral Relationships and Blame}

While concurring with Kelly that a criminal justice system of censure without blame can achieve these communicative goals, it seems to me that there are two problems with her proposal. The first one, which I will only mention in passing, concerns feasibility. Throughout her book, and especially in the third chapter, Kelly defends the distinction between the appraisal of agents, such as through blame, and the appraisal of acts. While the distinction is intelligible in theory, it might be less straightforward in practice when it comes to designing a criminal justice system of censure without blame. Some suggestions of how this could be achieved have been advanced, and range from eliminating any appeal to the idea of bad character in criminal proceedings, ${ }^{30}$ to devising guidelines on how offenders should be spoken to, ensuring that blaming and stigmatising practices do not take place. ${ }^{31}$ Nonetheless, more work needs to be done to delineate the outline of a criminal justice system of censure without blame.

The second problem, to which I dedicate the rest of this article, is the question of whether abandoning blame would also forego other important expressivist and communicative aims of the criminal justice system: aims that are not captured by the role that Kelly assigns to the public denunciation of crime. Many proponents of expressivist and communicative theorists of punishment argue that censure and blame are part of an exchange with the offender and an attempt at rational and moral persuasion aimed at the restoration of moral relationships. ${ }^{32}$ In what follows, I explore the possibility that a criminal justice system of censure without blame could incorporate this aim, by looking at the role of restorative justice. This is motivated by the conviction that the restoration of moral relationships is to be regarded as an important aim of the criminal justice system, as well as by some of Kelly's own claims about the nature of moral blame.

\footnotetext{
28 Duff, 82-88.

29 Joel Feinberg, 'The Expressive Function of Punishment':, Monist 49, no. 3 (1965): 397-423. Andrew Von Hirsch, Past or Future Crimes: Deservedness and Dangerousness in the Sentencing of Criminals (Manchester: Manchester University Press, 1985), chap. 5.

${ }^{30}$ Samuel H. Pillsbury, Judging Evil: Rethinking the Law of Murder and Manslaughter (New York: New York University Press, 1998), 84; Nicola Lacey, In Search of Criminal Responsibility: Ideas, Interest and Institutions (Oxford: Oxford University Press, 2016), chaps 3-5.

31 Nicola Lacey and Hanna Pickard, 'From the Consulting Room to the Court Room? Taking the Clinical Model of Responsibility Without Blame into the Legal Realm', Oxford Journal of Legal Studies 33, no. 1 (2012): 22.

32 Duff, Punishment, Communication, and Community. Bennett, The Apology Ritual.
} 
As I mentioned in the first section, one of Kelly's arguments against blame in the criminal justice system is grounded in the idea that moral blame is optional. In her view, while under certain circumstances blame can be appropriate, this response is always a matter of choice and it is perfectly open to victims also to react to wrongful actions with forgiving and compassionate attitudes. ${ }^{33}$ Kelly thereby rejects the widely-held Strawsonian dichotomy. This holds that when responding to wrongdoing one can choose between, on the one hand, blame and similar reactive attitudes and, on the other hand, an objective stance which does not regard the wrongdoer as a participant of moral relationships. ${ }^{34}$ She argues that forgiveness and compassion can be part of an exchange where we still regard the other person as a full moral agent and a participant of moral relationships. From these considerations, Kelly derives the conclusion that the criminal justice system should not mandate public blame. We cannot conclude that the state has a duty to express blame from the idea that blame is the only respectful response to wrongdoing in interpersonal cases, since that idea is mistaken. Whether blame is indeed appropriate in general, as well as in specific circumstances, can be the object of reasonable disagreement. ${ }^{35}$

While it is clear why the state's mandate to blame cannot be derived from the optional nature of blame, another question about the way in which blame can feature in the criminal justice system arises. Should the state give the victims of crime the choice to blame their perpetrators by creating institutional settings, such as restorative justice conferences, which allow this exchange to take place? In passing, Kelly mentions the possibility that in her proposed criminal justice system, courts could offer defendants the option to engage in restorative justice processes, if victims agree to do so. ${ }^{36}$ However, more needs to be said about this possibility.

Before replying to this question, I will briefly characterise the various practices that go under the heading of restorative justice. Restorative justice practices are processes in which various parties involved in or affected by the crime are brought to a conference. Typically, besides offenders and victims, this includes their supporters (family or friends) and sometimes other members of the community. These parties are in the position to exercise a degree of control over the process and the outcome of the conference. Prior to the conference, the offender must admit responsibility for the crime; however, the exchange with the victim and the community typically foster a deeper awareness of the harm done and its impact. The central aim of these conferences is to discuss the effects of the crime and what the offender can do to repair the harm done. Moreover, these conferences are aimed at the restoration of relationship and the reintegration of the offender through the acceptance of full responsibility and the openness to moral dialogue. ${ }^{37}$

\footnotetext{
33 Kelly, The Limits of Blame, 113-19.

34 See Lacey and Pickard, 'From the Consulting Room to the Court Room?' for another rejection of the Strawsonian assumption.

35 Kelly, The Limits of Blame, 119-21.

36 Kelly, 128.

37 Margaret Urban Walker, Moral Repair: Reconstructing Moral Relations after Wrongdoing (Cambridge: Cambridge University Press, 2006), 207-18.
} 
There are two sets of reasons to doubt that in the traditional settings of the criminal justice system the exchange of blame will take the form of a fruitful moral dialogue. Firstly, courts are ill-equipped for managing emotions, partly because during the trial there is little room for the discussion of contextual information about the offenders' life and psychology. ${ }^{38}$ Secondly, as I argued earlier, the exchange between the state and the individual is likely to have stigmatising effects. Therefore, communicative theories of punishment that consider such exchange central to punishment should rethink the settings where it would take place.

In my view, restorative justice settings are the appropriate environments for blaming the offender if blame is understood as a moral dialogue with the offender, the aim of which is acknowledging the harm done and the restoration of relationships. In these settings, the expression of blame can be a chance for the wrongdoer to reflect on his agency and, through the discussion about the crime and the support of others, bring about a change in his attitude and future conduct. Being confronted by one's victims with a first-hand account of the consequences of the criminal action allows the person responsible for it to fully appreciate its significance. ${ }^{39}$ Moreover, some recent studies have shown that the possibility of repentance and the likelihood of re-offending is related to how the offenders manage the shame and the guilt associated with being confronted for one's wrongdoing. ${ }^{40}$ The potentially devastating effects of shame are avoided when these negative feelings are confronted and the offender can focus and reflect on their action without coming to regard himself as an irredeemably bad person. ${ }^{41}$ This is more likely to happen in restorative justice settings. ${ }^{42}$ Because they allow a meaningful and effective dialogue between victims and offenders, restorative justice processes are the ideal settings to further the goals of the repair of damaged moral relationships and reconciliation between the offender, the victim and the broader political community. Restorative justice conferences are focused on making amends on the part of the wrongdoer and serve the function of reassuring the victim and the political community at large that the offender's commitment to the basic standards of treatment of each other is reinstated, thereby restoring relationships of trust and a sense of community. ${ }^{43}$

Therefore, institutionalising blame in this manner has various advantages: it can promote the restoration of relationships and the rehabilitation and reintegration of offenders, which valuable in itself as well as an instrument to reduce harm related to crime. By leaving the option open to victim of whether to engage in these

\footnotetext{
38 Toni M. Massaro, 'The Meanings of Shame: Implications for Legal Reform.', Psychology, Public Policy, and Law 3, no. 4 (April 1997): 645-704.

39 Victoria McGeer, 'Civilizing Blame', in Blame: Its Nature and Norms, ed. D. Justin Coates and Neal A. Tognazzini (Oxford; New York: Oxford University Press, 2013), 184-86.

40 Nathan Harris and Shadd Maruna, 'Shame, Shaming and Restorative Justice', in Handbook of Restorative Justice: A Global Perspective, ed. Dennis Sullivan and Larry Tifft (London: Routledge, 2008), 452-62.

41 Nicola Lacey and Hanna Pickard, 'To Blame or to Forgive? Reconciling Punishment and Forgiveness in Criminal Justice', Oxford Journal of Legal Studies 35, no. 4 (2015): 688-92.

42 Harris and Maruna, 'Shame, Shaming and Restorative Justice'.

43 Margaret Urban Walker, Moral Repair: Reconstructing Moral Relations after Wrongdoing (Cambridge: Cambridge University Press, 2006), 210-11.
} 
conferences, this way of institutionalising blame is immune to one of the critiques that Kelly directs against criminal blame: mainly that it mandates public blame disregarding the fact that blame is optional. Moreover, in virtue of it being a dialogue between victims and perpetrators, rather than the state and perpetrators, it also avoids the objections against criminal blame and its stigmatising nature that I discussed in the first section. In this sense, the dialogue that takes place in these settings resembles more closely the exchanges that take place in interpersonal morality.

However, matters are not as simple as they first appear. Leaving the option open to the victim to blame in restorative justice settings might seem to presuppose the view that all those who have committed a crime are appropriate targets for blame, if victims decide to express it. This would be incompatible with Kelly's claim that blameworthiness and liability to punishment are distinct, and that there are many cases where one is liable to be punished despite not being blameworthy. In her view, the conditions for punishment liability should be minimal rationality, rather than the full moral competence that is necessary for being an appropriate candidate for blameworthiness and blame. ${ }^{44}$

In replying to this objection it should be pointed out that while blame does feature in these proceedings-as well as other negative and potentially stigmatising attitudes and emotions, such as shame-its nature and role tends to be more in line with forward-looking accounts of these attitudes. In the case of shame, it has been often argued that, rather than the stigmatising shame, it is a restorative kind of shame which takes place in restorative justice settings. ${ }^{45}$ Similarly, in restorative justice settings we would find a kind of blame which is more in line with a functional account of blame which understands blame as an instrument of moral protest but also as a means for reflection and improvement of the agency of the offender and reconciliation. ${ }^{46}$ This kind of account, as well as yielding less stigmatising effects, is less focused on backward-looking considerations of blameworthiness and moral competence. Nonetheless, as Kelly suggests, even within this account of blame it would not be appropriate to convey blame towards someone who is not blameworthy. ${ }^{47}$

A more promising line of reply is to point at the fact that while the restorative justice processes do often encompass the exchange of blame, they are not exhausted by blame. Like exchanges in interpersonal morality, victims can decide which attitudes to display from a list that goes well beyond blame. This response, while not always perfectly calibrated, is often sensitive to facts about the wrongdoers, including whether they are blameworthy. Furthermore, given that the stated aim of restorative justice conferences is to repair the harm done and restore moral relationships, the exchanges taking place in these settings are further constrained than those of interpersonal morality. This should not just invite the exclusion of punitive and stigmatising attitudes but should also limit the expression of blame to cases where blame is both fitting and conducive to the goals of reparation and reconciliation. Therefore,

\footnotetext{
44 Kelly, The Limits of Blame, 114-21.

45 John Braithwaite, Eliza Ahmed, and Valerie Braithwaite, 'Shame, Restorative Justice, and Crime.', in Taking Stock: The Status of Criminological Theory, ed. Francis T. Cullen (New Brunswick, Nj: Transaction, 2006), 397-417.

46 McGeer, 'Civilizing Blame'.

47 Kelly, The Limits of Blame, 50-51.
} 
while blame would figure in restorative justice exchanges, it would not always be centre stage. Nevertheless, allowing blame to play a role in the criminal justice system in restorative justice settings is important insofar as blame is part of a moral dialogue between the offenders and the victim aimed at restoring moral relationship. By supplementing Kelly's proposal in this way, the result is a criminal justice system which incorporates the valuable features and goals of communicative theories of punishment, without being exposed to the criticisms to which a blame-centric criminal justice system is vulnerable.

\section{Conclusion}

In this paper, I have discussed Kelly's view about the role of blame in the criminal justice system with two aims. Firstly, I have tried to strengthen her case for a criminal justice system without blame by lending further support to her view that criminal blame is inherently stigmatising. In so doing, I have pointed out and discussed the often-overlooked distinction between criminal and moral blame which makes the former, unlike the latter, objectionable. Secondly, in addressing the question of whether a criminal justice system without blame fails to incorporate some important aims articulated by expressivist and communicative theories of punishment, I have argued that the goal of restoring moral relationships invites us to find a role for blame, albeit a very different and more limited one. Blame would feature in the moral dialogue between victims and wrongdoers, aimed at repentance and reconciliation, which takes place in restorative justice settings.

Funding Open Access funding enabled and organized by Projekt DEAL.

Open Access This article is licensed under a Creative Commons Attribution 4.0 International License, which permits use, sharing, adaptation, distribution and reproduction in any medium or format, as long as you give appropriate credit to the original author(s) and the source, provide a link to the Creative Commons licence, and indicate if changes were made. The images or other third party material in this article are included in the article's Creative Commons licence, unless indicated otherwise in a credit line to the material. If material is not included in the article's Creative Commons licence and your intended use is not permitted by statutory regulation or exceeds the permitted use, you will need to obtain permission directly from the copyright holder. To view a copy of this licence, visit http://creativecommons.org/licen ses/by/4.0/.

Publisher's Note Springer Nature remains neutral with regard to jurisdictional claims in published maps and institutional affiliations. 